\title{
A importância da utilização de práticas de metodologias ativas de aprendizagem na formação superior de profissionais da saúde
}

\author{
Pablo Guilherme Caldarelli \\ Docente do Departamento de Medicina Oral e Odontologia Infantil - UEL \\ Doutorado em Odontologia (Cariologia) - UNICAMP \\ Mestrado em Odontologia em Saúde Coletiva - UNICAMP \\ Esp. em Ativação de Processos de Mudança na Formação Superior de Profissionais de Saúde - FIOCRUZ \\ Graduação em Odontologia - UEL \\ $\triangle$ pablocaldarelli@hotmail.com
}

As Instituições de Ensino Superior (IES) devem atender às necessidades sociais que levem à melhorias no desenvolvimento sustentável e nas condições de saúde das populações, por meio da formação de trabalhadores com habilidades e qualificações técnicas sensíveis às necessidades dos diversos tipos de populações. Além disso, devem incentivar a promoção de saúde entre diferentes grupos profissionais, estudantes e instituições, para que estes sujeitos aumentem e melhorem o controle sobre sua saúde. $\mathrm{Na}$ formação superior de profissionais da saúde, a inserção e utilização de práticas de metodologias ativas de aprendizagem pode ser considerada como um caminho metodológico capaz de orientar a prática pedagógica de docentes preocupados com o desenvolvimento dessas habilidades e competências em seus estudantes, visando sua autonomia intelectual.

Entretanto, sabe-se que o processo ensino-aprendizagem é complexo, apresenta um caráter dinâmico e não acontece de forma linear, como uma somatória de conteúdos acrescidos aos anteriormente estabelecidos. É neste contexto que as metodologias ativas surgem como um importante instrumento na utilização da problematização como estratégia de ensino-aprendizagem, com o objetivo de alcançar e motivar o estudante, que detém, examina, reflete, relaciona a sua história e passa a ressignificar suas descobertas.

Algumas práticas de metodologias ativas de aprendizagem têm como ponto de partida a realidade vivenciada pelo estudante, ou seja, a parcela da realidade onde o tema que está sendo ou será trabalhado está acontecendo na vida real. Assim, ao desenvolver trabalhos com esta perspectiva metodológica, os estudantes são levados a observar a realidade de maneira atenta e irão identificar aquilo que na realidade está se mostrando 
como carente, inconsistente, preocupante, necessário, enfim, problemático. Neste cenário, os estudantes estão problematizando a realidade e verificando o que necessita ser trabalhado, corrigido ou aperfeiçoado. Além disso, as metodologias ativas baseadas na problematização podem levar o estudante ao contato com as informações e à produção do conhecimento, principalmente, com a finalidade de solucionar os impasses e promover o seu próprio desenvolvimento. Ao perceber que a nova aprendizagem é um instrumento necessário e significativo para ampliar suas possibilidades e caminhos, esse poderá exercitar a liberdade e a autonomia na realização de escolhas e na tomada de decisões. Em oposição aos processos de aprendizagem tradicionais e de recepção, em que os conteúdos são entregues ao aluno em sua forma final e acabada, a problematização está apoiada nos processos de aprendizagem por descoberta, e os conteúdos são oferecidos na forma de problemas.

As metodologias ativas permitem também a articulação entre a universidade, o serviço e a comunidade, por possibilitar uma leitura e intervenção consistente sobre a realidade, valorizar todos os atores no processo de construção coletiva e seus diferentes conhecimentos e promover a liberdade no processo de pensar e no trabalho em equipe. $\mathrm{Na}$ problematização, o sujeito percorre algumas etapas e, nesse processo, irá refletir sobre a situação global de uma realidade concreta, dinâmica e complexa, exercitando a práxis para formar a consciência da mesma. Problematizar, portanto, não é apenas apresentar questões, mas, sobretudo, expor e discutir os conflitos inerentes e que sustentam o problema.

Contudo, é importante destacar que as necessidades de mudanças em estratégias educacionais nas áreas de saúde vão além da utilização de novas técnicas de ensinoaprendizagem, passando pelo rearranjo nos conteúdos dos cursos. Baseiam-se, sobretudo na cultura do ensino, no ensino e na aprendizagem orientados por objetivos, princípios de aprendizado do adulto e, por fim, a aplicação metodologias ativas de aprendizagem. Por isso, as Diretrizes Curriculares Nacionais (DCN) e as estratégias de ensino-aprendizagem devem ser constantemente discutidas em seu contexto de determinantes: o Projeto Político Pedagógico (PPP) da instituição, a organização curricular, a visão de ciência e de conhecimento e a função social das Instituições de Ensino Superior (IES). Dessa forma, a flexibilidade curricular torna-se um dos grandes facilitadores para que as metodologias ativas possam ser implantadas, sendo sempre considerada a prática de avaliação, integrada à reflexão e transformação. 
Considerando todos os aspectos discutidos, um dos grandes desafios para as Instituições de Ensino Superior (IES), no processo de inserção e utilização de metodologias ativas de aprendizagem, é estimular, capacitar o corpo docente e proporcionar infraestrutura para o emprego dos variados métodos de ensino-aprendizagem. Além de prover as condições estruturais, a IES também deve manter treinamento e capacitação contínua para seu corpo docente. A rede instituída de apoio ao ensino, disponível ao docente e ao aluno, faz-se necessária para planejamento e execução de intervenções no currículo. Em suma, as IES devem planejar e conduzir os esforços educacionais para prover estrutura e cenários diversificados e específicos, definir diretrizes propiciadoras ao uso das metodologias ativas; promover capacitação do corpo docente e a avaliação sistemática da eficácia de sua utilização.

\section{CONSIDERAÇÕES FINAIS}

A utilização de práticas de metodologias ativas de aprendizagem apresenta um grande potencial para apoiar a implementação e consolidação das Diretrizes Curriculares Nacionais (DCN) nos cursos de graduação na área da saúde, estando diretamente relacionada com a formação de profissionais humanistas, críticos / reflexivos, decisivos e desenvoltos, capazes de atuar em todos os cenários de práticas, com base no rigor técnico e científico, pautado em princípios éticos, legais e na compreensão da realidade social, cultural e econômica do seu meio, dirigindo sua atuação para a transformação da realidade em benefício da sociedade.

\section{REFERÊNCIAS BIBLIOGRÁFICAS}

GANASTASIOU, L.G.C.; ALVES, L.P. Estratégias de Ensinagem. In: Processos de ensinagem na universidade: Pressupostos para as estratégias de trabalho em aula. Santa Catarina: Editora Joinville, 2007.

BERBEL, N.A.N. A Metodologia da Problematização com o Arco de Maguerez: Uma reflexão teóricoepistemológica. Paraná: Editora UEL, 2014.

BERBEL, N.A.N. Metodologia da Problematização - Fundamentos e aplicações. Paraná: Editora UEL, 1999. 
BRASIL. CNE. Resolução CNE/CES 3/2002 [internet]. Diário Oficial da União, Seção 1, p.10; Brasília, 4 de março de 2002. Disponível em <http://portal.mec.gov.br/cne/arquivos/pdf/CES032002.pdf>. Acesso em 02 de novembro de 2016.

CYRINO, E.G; TORALLES-PEREIRA, M.L. Trabalhando com estratégias de ensino-aprendizado por descoberta na área da saúde: a problematização e a aprendizagem baseada em problemas. Cad. Saúde Pública, Rio de Janeiro, v. 20, n. 3, p. 780-788, 2004. Disponível em: <http://www.scielo.br/pdf/csp/v20n3/15.pdf>. Acesso em 02 de novembro de 2016.

FEUERWERKER, L.C.M. Gestão dos processos de mudança na graduação em medicina. In: Educação médica em transformação: Instrumentos para a construção de novas realidades. São Paulo: Editora Hucitec, 2004.

MITRE, S.M. et al. Metodologias ativas de ensino-aprendizagem na formação profissional em saúde: Debates atuais. Ciênc. Saúde Coletiva, Rio de Janeiro, v. 13, supl. 2, p. 2133-2144, 2008. Disponível em <http://www.scielo.br/pdf/csc/v13s2/v13s2a18.pdf>. Acesso em 02 de novembro de 2016.

MORITA, M.C. et al. Implantação das Diretrizes Curriculares Nacionais em Odontologia [Internet]. Maringá: $\quad$ Editora Dental $\quad$ Press, $2007 . \quad$ Disponível em <http://abeno.org.br/arquivos/downloads/download_20111109153352.pdf>. Acesso em 02 de novembro de 2016.

SOUZA, C.S.; IGLESIAS, A.G.; PAZIN-FILHO, A. Estratégias inovadoras para métodos de ensino tradicionais aspectos gerais. Rev. Med. (Ribeirão Preto), São Paulo, v. 47, n. 3, p. 284-292, 2014. Disponível em <http://revista.fmrp.usp.br/2014/vol47n3/6 Estrategias-inovadoras-para-metodos-de-ensino-tradicionaisaspectos-gerais.pdf>. Acesso em 02 de novembro de 2016. 